\title{
LA LEGITIMACIÓN DEL VENDEDOR CITADO DE EVICCIÓN PARA ALEGAR LA PRESCRIPCIÓN ADQUISITIVA Y EXTINTIVA
}

\section{THE LEGITIMATION OF THE SELLER TO OPPOSE THE ACQUISITIVE AND EXTINCTIVE PRESCRIPTION}

Maximiliano Silva Hanisch*

\section{RESUMEN}

El presente artículo busca examinar si el vendedor citado de evicción tiene legitimación activa para oponer la usucapión y la prescripción extintiva a favor del vendedor en el juicio de molestia. El trabajo se enfoca en una revisión doctrinaria y jurisprudencial de esta cuestión, analizándose el instituto a la luz de las normas procesales y civiles vigentes en nuestro país.

Palabras claves: citación de evicción; prescripción; legitimación.

\section{AbSTRACT}

The following article seeks to examine if the seller can oppose the acquisitive and or the extinctive prescription in the name of the defended purchaser when he is sued to dispossession the purchased property. The present paper focuses on a doctrinal review and the analysis of the institute under the civil and procedural rules in force in our country.

Keywords: dispossession of property; acquisitive prescription; legitimation to oppose.

\footnotetext{
* Doctor en Derecho. Profesor de Derecho Procesal. Universidad Finis Terrae. Dirección Postal: Avenida Pedro de Valdivia 1509, Providencia, Chile. Correo electrónico: msilvah3@ uft.edu.
}

Recepción: 2020-01-30; aceptación: 2020-08-12. 


\section{INTRODUCCIÓN}

Si se declara la evicción de la cosa, por regla general el vendedor citado de evicción deberá responder del despojo que ocurra, conforme disponen los arts. 1838 y 1839 del $C C$, por lo que mucho le interesará oponer la mejor defensa posible para evitar asumir la contingencia económica de la evicción, y dentro de las defensas y alegaciones que puede oponer, las excepciones tienen un lugar fundamental en el amparo que debe desplegar en favor del comprador.

En este sentido, el vendedor intentará por todos los medios que se rechace la demanda, lo que no genera mayores cuestionamientos respecto de la generalidad de las defensas y excepciones, salvo en relación con la prescripción, que será una de las defensas más importantes que podrá oponer, y de ella en particular la usucapión, en atención al carácter real que generalmente tendrá la demanda que interponga el tercero contra el comprador respecto de la cosa adquirida, por lo que en la presente investigación se analizará si está legitimado o no para oponer dichas excepciones.

\section{LA INTERVENCIÓN DEL VENDEDOR CITADO DE EVICCIÓN}

\section{El objeto del juicio de molestia y la obligación de defensa}

Doctrinariamente, el objeto del proceso es el caso que se presenta ante el tribunal y que ha de resolverse, es decir, la res de qua agitur ${ }^{1}$. En razón del principio dispositivo, el tribunal es requerido por el demandante para que resuelva el problema que se le plantea, y la forma en la que se le presenta la controversia es a través de una concreta pretensión de tutela jurisdiccional, de forma tal que el objeto, en definitiva, es lo requerido al tribunal, existiendo, en consecuencia, una identidad entre el objeto del proceso y la pretensión procesal ${ }^{2}$.

En este sentido, Jaime Guasp concibe la pretensión procesal como:

"un acto procesal y al mismo tiempo el objeto del proceso, integrando este objeto, no en cuanto acción que se realiza en un cierto momento, sino en cuanto acto ya realizado que, por ese mismo

${ }^{1}$ TAPIA (2000), p. 17.

${ }^{2}$ De la Oliva (2005), pp. 26-27. Coloquialmente la palabra 'objeto' denota lo que está frente a un sujeto o se pone frente a él, de forma tal que lo que debe ser resuelto en un juicio es "la cosa" que se pone frente al juez, a efecto de que este lo resuelva, op. cit., p. 24. 
carácter de estado que imprime a la realidad una vez que ha influido sobre ella, hace girar en torno a sí misma el resto de los elementos que aparecen en la institución procesal"3,

por lo que la pretensión es un requerimiento que un sujeto hace a otro frente a un tribunal, para que se le conceda -por las razones que invoca-, algo respecto de ese otro sujeto ${ }^{4}$. De esta forma, sus elementos identificadores son las partes que intervienen, una determinada petición, y el fundamento en virtud del cual ello se pide, a los que se agrega el interés procesal, que, en síntesis, es la necesidad que tiene el actor de la actividad jurisdiccional para la adecuada protección que reclama ${ }^{5}$.

Vale decir, en resumidas cuentas, el objeto del proceso es lo que debe decidirse, y en el juicio de molestia consiste en determinar si la cosa pertenece realmente al comprador o, si por el contrario, pertenece total o parcialmente al tercero que demanda, tanto respecto de si fue debidamente transferida como si está o debe estar de alguna forma gravada ${ }^{6}$.

En este juicio se desarrolla la obligación de defensa que debe desplegar el vendedor citado de evicción, en virtud de la cual debe instar a que se rechace la demanda deducida contra el comprador, y su participación se justifica en atención a que lo que debe decidir el tribunal versa sobre un hecho anterior a la compra, y que, en principio, ocurrió mientras él era el dueño del bien que con posterioridad vendió. Por esta razón, aun cuando la alegación que hace el actor es totalmente extraña al comprador demandado, dado que los hechos se verificaron antes de que él fuera el propietario de la cosa, la demanda debe necesariamente deducirse en su contra, por ser él el actual poseedor del bien que se reclama.

Así, en estricto rigor, la litis fáctica es entre el reivindicante y el vendedor, aun cuando la pretensión deba dirigirse en contra del comprador y,

${ }^{3}$ Guasp (1985), p. 66.

${ }^{4}$ De la Oliva (2005), p. 28. Sin perjuicio de que no se comparte íntegramente el entendimiento del autor sobre el alcance del concepto de derecho de acción y pretensión, esas diferencias no son relevantes para lo que se está revisando. Para el entendimiento del autor sobre este punto véase De la Oliva et al. (2012), p. 325 y ss. Gonzalo Cortez agrega que es una declaración de voluntad petitoria, en términos que es "la petición fundada que se dirige a un órgano jurisdiccional, frente a otra persona, sobre un bien determinado". CoRTez (2014), p. 127.

${ }^{5}$ Sobre el interés procesal, cómo integra la pretensión y las consecuencias de su desaparición sobrevendida, véase Silva (2017).

${ }^{6}$ En caso de que conjuntamente se deduzcan otras pretensiones en contra del comprador que no tengan relación con la pretensión real deducida, el vendedor que comparece no debe intervenir en ellas, debiendo limitar su intervención única y exclusivamente a la demanda sobre la cosa, sin que se le admitan alegaciones o pruebas respecto de las demás pretensiones. SERRA (1969), p. 308. 
por ello, sea él quien sufra directamente las consecuencias de un eventual despojo ${ }^{7}$.

A su vez, la obligación de defensa exige al vendedor amparar al comprador en el dominio y posesión pacífica de la cosa adquirida en el contexto de una pretensión dirigida en contra del comprador, y cuyo objeto sea sustraer de su patrimonio todo o parte de la cosa comprada, a efecto de que disminuyan o desaparezcan los derechos que el adquirente tenía o creía tener respecto de la cosa comprada, tal como lo dispone el art. 1838 del $C C$.

En este contexto, el adquirente puede citar de evicción a su vendedor conforme lo disponen los arts. 584 a 587 del $C P C$, a efecto de que comparezca en su defensa e inste al rechazo de la demanda, so pena de verse obligado a indemnizar los perjuicios que sufra el comprador a causa del despojo. Sin perjuicio de las consecuencias que pueda traerle, al ser debidamente notificado, el vendedor es libre de intervenir o no en el juicio de molestia.

Si el vendedor no comparece, continuará sin más trámite el juicio de molestia luego de vencido el plazo señalado en el art. 587 del $C P C$, por lo cual será el comprador quien deberá asumir íntegramente la defensa del juicio de molestia, sin perjuicio de que por regla general, el tradente será responsable de la evicción que se declare, pudiendo reclamarse su responsabilidad en el juicio indemnizatorio que al efecto se deduzca.

En caso de que el vendedor comparezca, "se seguirá contra él solo la demanda", según el decir del art. $1844 \mathrm{del} C C$, y este apersonamiento del vendedor implica que deberá actuar como si él fuera el demandado según se referirá en el acápite siguiente, a efecto de lograr que la demanda sea rechazada y así no tener que responder por la evicción. Para este objetivo, la ley le permite desplegar todos los recursos defensivos de los que dispone, casi de la misma forma en la que lo haría de ser él el demandado, aunque con ciertos matices y limitaciones indirectas, en razón de que la ley sancionará al comprador que no opuso "alguna defensa o excepción suya”, según refiere el art. 1843 inc. tercero del $C C$, según se analizará.

Así, que el vendedor sea o no obligado a indemnizar se evalúa a la luz del resultado del juicio de molestia, en términos que si se desestima la pretensión deducida, el comprador no puede reclamarle nada, aun cuando su desidia en la defensa haya sido absoluta, pues el hecho preciso que hace nacer su obligación de indemnizar no es el mayor o menor compromiso o diligencia que haya tenido para que la demanda fuera rechazada, sino, simplemente, que se verifique la evicción, vale decir, que haya un despojo total o parcial de la cosa respecto del comprador, y si ello no ocurre, aun

${ }^{7}$ OCAÑA (1997), p. 607. 
cuando el vendedor no haya prestado ninguna ayuda ni asistencia para que ese resultado positivo se verificara, la ley simplemente no lo hace responsable, salvo la excepcional hipótesis del art. $1855 \mathrm{del} C C^{8}$.

\section{La intervención del vendedor según el art. 1844 del $\mathrm{CC}^{9}$}

En el ordenamiento jurídico nacional, entender la obligación de defensa que asume el vendedor citado de evicción que comparece al juicio de molestia, se traduce en comprender el sentido y alcance del art. 1844 del $C C$, a efecto de desentrañar en qué calidad intervendrá el tradente.

$\mathrm{Al}$ respecto, cuando el art. 1844 del CC señala: "si el vendedor comparece, se seguirá contra él solo la demanda", se entiende que, si bien la literalidad de la norma sugiere que el tradente pasará a ser el demandado

${ }^{8}$ La reclamación que permite citar de evicción al tradente puede tramitarse en cualquier clase de procedimiento, siempre que sea una reclamación jurisdiccional contenciosa civil.

No hay una limitación respecto del juicio ordinario, pues la Tercera Comisión Revisora del Proyecto de Código de Procedimiento Civil cambió la ubicación del título pertinente, pasando del libro II al II del Código de Procedimiento Civil para darle aplicación general, aun cuando hubiera sido más correcto incorporarlo al libro I. En este sentido, en las "Actas de la comisión mista de senadores y diputados encargadas de informar sobre los proyectos de códigos de procedimiento civil i criminal", se señaló: "la citación de evicción no puede estimarse como una incidencia propia del juicio ordinario i que, en consecuencia, no debe figurar el título vi que trata de dicha citación en el libro II, que se refiere solo al juicio ordinario, sino entre los juicios especiales cuyo procedimiento establece el libro III". SIN AUTOR (1901), pp. 100-101.

Así lo ha resuelto, por lo demás, la Corte de Apelaciones de Santiago: "Que el derecho correlativo del comprador a pedir la citación de evicción puede ejecutarlo en cualquier clase de juicio que en su contra se interponga, tanto porque el Código Civil, impone, en términos generales, al vendedor la obligación de amparar al comprador en el dominio y posesión de la cosa vendida, sin condicionar dicha obligación a determinados actos perturbatorios, o a determinadas formas en que la perturbación pudiere producirse, cuanto que la perturbación pudiera producirse, cuanto porque el Código Procesal, no hace a su respecto distinción alguna, incluyendo en el libro III, que trata de los juicios especiales, un título independiente que corresponde a la citación de evicción que en el proyecto respectivo figuraba en el libro II, que sólo se refiere al juicio ordinario, como consta del acta de la sesión $\mathrm{N}^{\circ} 14$, de la Tercera Comisión Revisora.

Que la ley no ha limitado entonces la procedencia de la citación de evicción a procedimiento determinado, ni existe razón alguna emanada de su naturaleza ni de la tramitación a que está sometida, que impida hacer uso de ella en otros juicios que no sean ordinarios y en que se produzca el evento exigido para que el comprador pueda solicitar la comparecencia de su vendedor a defenderlo en el dominio o posesión pacífica de la cosa comprada". Enrico, José con Antonio Aros (1948).

${ }^{9} \mathrm{El}$ análisis exhaustivo de esta cuestión está contenido en la obra La citación de evicción en la compraventa. Aspectos procesales y civiles, aceptada a publicación por la Editorial Tirant lo Blanch, y que será publicada el año 2020. 
del pleito, como lo entiende la doctrina nacional ${ }^{10}$, ello no es correcto, porque, en definitiva, esta intervención no modifica de ninguna forma la pretensión deducida, en términos tales que con el advenimiento del vendedor al proceso, la reclamación del actor no pasará a dirigirse en su contra, ni tampoco dejará de dirigirse contra el comprador.

Esta norma simplemente le da al vendedor una participación preponderante en el pleito, que se traduce en que pasa a la primera línea de defensa, a efecto de que simplemente "se comporte" como si fuera el demandado -pese a que no lo es-, por expresa disposición de la ley.

Pero solo "se comporta" como demandado, pues solo en apariencia tendrá dicha calidad, ya que interviene en un conflicto que jurídicamente le es ajeno en lo inmediato, y respecto de una pretensión que no se dedujo en su contra, por lo que en esencia su intervención es la de un coadyuvante del comprador, pues es un tercero respecto de la controversia que es planteada por el demandante contra el adquirente demandado, pero con la particularidad de que por expresa exigencia legal, deberá desplegar gestiones de defensa mucho más intensas que las de un coadyuvante ordinario, debiendo él sustentar en primer término la defensa del pleito, razón por la cual se debe comportar y actuar como si la demanda se siguiera en su contra.

A su vez, esta primera parte del art. 1844 del $C C$ es complementada por la segunda, que señala: "pero el comprador podrá siempre intervenir en el juicio para la conservación de sus derechos", pues si la ley le da un realce especial al vendedor que comparece, lo propio es que desplace a una segunda línea al comprador, pero no por ello este dejará de ser el único y exclusivo sujeto pasivo de la pretensión, sino que se verifica una ficción en virtud de la cual la disputa se da entre el actor y el vendedor, pues la disputa fáctica se da precisamente entre ellos, en términos que los hechos en los que se funda son totalmente ajenos al comprador, aunque necesariamente él debió ser demandado, porque era el poseedor de la cosa que el tercero pretende reclamar ${ }^{11}$.

${ }^{10}$ En general la doctrina procesal y civil postulan que el vendedor pasa a ser el demandado, ya sea diciendo esto directamente o parafraseando el art. 1844 del $C C$, sin considerar las consecuencias de ello, como entre otros, ALESSANDRI (2003), tomo II, volumen I, p. 106; Casarino (2005), p. 89; Maturana (2009), p. 68; Luis Claro Solar, apuntes de VARAS Y VERGARA (1908), p. 234.

${ }^{11}$ La doctrina nacional, por el contrario, entiende que según el art. 1844 del $C P C$, es el comprador quien pasa a ser el coadyuvante del vendedor. Esta cuestión es sustentada, entre otros, por Alessandri (2003), tomo iI, volumen i, p. 106; MeZA (2010), p. 68; VodanoviC (1942), p. 400; Stoehrel y MuÑoz (1961), p. 72. 


\section{Las actitudes que puede adoptar el vendedor citado de evicción respecto de la demanda deducida contra el comprador}

En caso que se acoja la demanda del tercero y la cosa resulte evicta, por regla general el vendedor deberá indemnizar al comprador, según dispone el art. 1847 del $C C$, y atendida la particular forma de intervenir en el juicio de molestia (art. 1844 del CC), la ley le confiere la plenitud de facultades defensivas para instar a que la demanda sea rechazada, pero ellas necesariamente deben adecuarse tanto a la calidad en la que comparece como al hecho de que no defiende una relación sustancial propia.

$\mathrm{Al}$ efecto, el vendedor que interviene tiene -en principio-, las mismas facultades que cualquier otro demandado, en términos que puede hacer alegaciones formales, allanarse a la demanda con ciertas restricciones y puede entrar al fondo de la discusión, ya sea negando las alegaciones o las interpretaciones jurídicas esgrimidas o, incluso, oponiendo excepciones materiales ${ }^{12} \mathrm{y}$, de ellas, interesa analizar la prescripción adquisitiva y extintiva, particularmente si está legitimado para oponerlas en beneficio del comprador demandado.

\section{Las defensas de fondo que puede oponer el vendedor en calidad de citado de evicción}

Las excepciones de fondo son un tipo de defensas que puede oponer el demandado, distintas de la defensa negativa ${ }^{13}$, y se caracterizan porque no

${ }^{12}$ Sobre la alternativa de no contestar la demanda se está ante un caso particular, pues ello solo podrá ocurrir si previamente opone alegaciones formales o hace cualquier tipo de intervención en el pleito, pues si luego de ser citado simplemente opta por no hacer nada -no contestando la demanda-, el efecto que tendrá su silencio no será el de una contestación o defensa tácita, deviniendo en una actitud de rebeldía, sino que en este caso simplemente será excluido del proceso por aplicación del art. 587 del $C P C$, que dispone que en caso de no intervenir el vendedor "vencido el término de emplazamiento, continuará sin más trámite el procedimiento". Sobre la rebeldía en el proceso civil, véase Carrasco (2010).

${ }^{13}$ La defensa negativa consiste en contestar la demanda sobre la base de una negación de los elementos de hecho o de derecho que sirven de fundamento a la reclamación jurisdiccional, contraviniendo la verdad de los presupuestos fácticos alegados, o las consideraciones o interpretaciones jurídicas esgrimidas. Esta es una mera negativa, que no lleva consigo ninguna afirmación respecto de un hecho distinto del señalado en el libelo, y que tiene como consecuencia que la carga de la prueba recaerá exclusivamente sobre el demandante de acuerdo con el art. 1698 del $C C$, pues una defensa de este tipo no añade ningún hecho que el demandado deba probar.

Sobre el punto Eduardo Couture señala: "para poder oponerse a una demanda no se necesita tener razón. El demandado también puede actuar con conciencia de su sinrazón y oponerse a una demanda fundada. Pero su razón o falta de razón no pueden ser juzgadas 
controvierten la efectividad del derecho alegado por el actor, sino que se oponen a la pretensión deducida al alegar hechos extintivos o modificatorios en su contra, y que tienen respecto de ella un efecto invalidatorio, modificatorio o extintivo ${ }^{14}$. Estas excepciones son más amplias que los modos de extinguir las obligaciones, pues también contemplan consideraciones de otra índole como -entre otras-, la exceptio non adimpleti contractus.

Estas excepciones tienen la particularidad de que al alegarlas dan por supuesta la existencia de la pretensión a la que se oponen, pero agregan un hecho de tal entidad que lleva a desestimarla.

En relación con las excepciones que puede oponer el vendedor que comparece al juicio de molestia, Adolf Wach señala que no puede oponer excepciones materiales o procesales personales, porque no es el dueño del pleito ${ }^{15}$. Esta consideración se sustenta en que el vendedor solo es parte en sentido procesal, pero no lo es en sentido material de la disputa, de forma tal que como la pretensión no se dirige en su contra, las alegaciones y defensas que puede oponer se limitan a cuestiones argumentativas o excepciones que no tengan relación con consideraciones personales, pues el vendedor no tiene vínculo directo ni con el actor ni con la cosa reclamada.

Este entendimiento lo recoge parcial e indirectamente el inc. tercero del art. 1843 del $C C$, que señala que el vendedor podrá eximirse de sanear la evicción si el comprador no opuso alguna excepción o defensa "suya", al señalar:

"si el comprador omitiere citarle, y fuere evicta la cosa, el vendedor no será obligado al saneamiento; y si el vendedor citado no compareciere a defender la cosa vendida, será responsable de la evicción; a menos que el comprador haya dejado de oponer alguna defensa o excepción suya, y por ello fuere evicta la cosa".

Las defensas y excepciones a que hace referencia esta norma son las "suyas" del comprador, cuestión graficada en la ley precisamente con esa expresión. A su vez, la determinación de si una excepción o defensa es o no "suya" del comprador, es una cuestión que queda a criterio del tribunal,

en el transcurso del juicio, para detener o para no dar andamiento a su oposición, sino que se actúa tal como si el derecho a oponerse fuera perfecto, hasta el momento de la sentencia. El demandado, con razón o sin ella, reclama al juez que se le absuelva de la demanda; nadie puede privarle de ese derecho. Las consecuencias de esta actitud son graves y el demandado las asume bajo su responsabilidad y con consecuencias. Pero ello atañe a la moral del proceso y a sus derivaciones jurídicas; lo que aquí se estudia es la ontología, no la ética”. Couture (2010), p. 78.

${ }^{14}$ Op. cit., pp. 73-74.

${ }^{15}$ WACH (1979), pp. 447-448. 
aunque un punto de orientación para determinarlo es analizar si un tercero que interviene en calidad de coadyuvante del demandado -un interviniente adhesivo ordinario-, podría oponer válidamente esa excepción, a efecto de que se rechace la demanda. En caso de que pudiera hacerlo, entonces no es una excepción "suya" del comprador, pero si no puede esgrimirla, entonces es una excepción o defensa propia del comprador.

En este sentido, la lógica subyacente al art. 1843 del $C C$ para limitar la eventual responsabilidad del vendedor en caso de que se declare la evicción, se enfoca en que si el comprador opuso las excepciones "suyas", y aun así la cosa fue evicta, entonces no puede culpárselo de la evicción, por lo que el vendedor debe responder del despojo, ya que de haber comparecido, sí podría haber cambiado el destino del pleito, pues la defensa que en conjunto podrían haber desplegado habría sido la más completa posible, contemplando las excepciones "suyas" del comprador, que solo él puede oponer, y las demás defensas que podría haber opuesto el vendedor.

Esto plantea una cuestión de suma relevancia, pues la norma en comento dispone que el vendedor no responderá de la evicción si se verifican copulativamente los siguientes supuestos:

i) que el vendedor sea citado de evicción en tiempo y forma;

ii) que el vendedor no comparezca al juicio de molestia;

iii) que el comprador deje de oponer una defensa o excepción "suya" y

iv) que esa sea la causa determinante para acoger la demanda y declarar la evicción de la cosa.

Pero el tenor del art. 1843 del $C C$, en definitiva, no resuelve si el vendedor puede o no alegar la prescripción, sino qué ocurre si, no compareciendo, el vendedor no alega una excepción "suya"; y dado que el vendedor solo pasa a ser formalmente el demandado, pues no es el destinatario de la pretensión -y por ello no reemplaza al comprador en la relación que este tiene con la cosa, ni tampoco en la relación que el demandado pueda tener con el actor-, debe analizarse cuidadosamente si el vendedor puede o no oponer las excepciones o defensas "suyas" del comprador y, en especial, la prescripción.

\section{LA LEGITIMACIÓN ACTIVA DEL VENDEDOR}

PARA OPONER LA PRESCRIPCION COMO DEFENSA EN EL JUICIO DE MOLESTIA

En los siguientes párrafos se analizará la prescripción en cuanto medio de defensa, tanto en su dimensión adquisitiva como extintiva, pues ambas pueden esgrimirse, a efecto de lograr que la pretensión del tercero deducida contra el adquirente sea, en definitiva, rechazada, evitando así la evicción de la cosa. 
El título XuI del libro IV del $C C$ analiza la prescripción, destinando el primer párrafo a consideraciones generales sobre este instituto, el segundo a la usucapión, el tercero a la prescripción extintiva y el cuarto a las acciones que prescriben en corto tiempo, orden que emuló al Code, y respecto del cual mucho se ha escrito, tanto para criticarlo como para defenderlo, pero tal como refiere René Abeliuk, dicha discusión resulta bizantina ${ }^{16}$.

$\mathrm{El}$ análisis que se hará tiene la particularidad de que revisará si en cada caso el vendedor que comparece como citado de evicción está o no facultado para alegar dichas cuestiones, revisándose por separado la usucapión y la prescripción extintiva, pues cada una tiene particularidades especiales.

\section{En relación a la usucapión, ¿puede el vendedor citado de evicción alegarla en favor del comprador?}

Los presupuestos de la usucapión están contemplados en los arts. 2498 y 2500 del $C C$, y para que opere deben concurrir dos elementos fácticos: posesión y transcurso de plazo, debiendo ambos elementos predicarse respecto de quien pasará a ser dueño de la cosa.

En relación con la posesión, Andrés Bello adoptó la tendencia subjetiva, concibiéndola como

"la tenencia de una cosa determinada con ánimo de señor o dueño, sea que el dueño o el que se da por tal tenga la cosa por sí mismo, o por otra persona que la tenga en lugar y a nombre de él” (art. 700 del $C C)^{17}$.

Respecto del plazo, depende tanto del tipo de posesión como de la naturaleza del bien. La prescripción adquisitiva ordinaria exige la posesión regular por dos años en caso de bienes muebles y cinco en caso de inmuebles, de acuerdo con lo dispuesto en los arts. 2507 y 2508 del $C C$. Por su parte, la usucapión extraordinaria exige posesión irregular por diez años, tanto respecto de muebles como de inmuebles, según lo regulado por los arts. 2510 y 2511 del $C C$.

Pero además de los presupuestos fácticos señalados, la prescripción debe ser alegada, tal como señala el art. 2493 del $C C$, que dispone: "el que quiera aprovecharse de la prescripción debe alegarla; el juez no puede declararla de oficio".

${ }^{16}$ Abeliuk (2008), tomo II, p. 1188.

${ }^{17}$ Una síntesis de los autores que califican la posesión como un hecho o como derecho en Peñailillo (2019), p. 930 y ss. 
La duda que se plantea es si el vendedor que comparece al pleito puede o no alegar la prescripción adquisitiva en favor del comprador demandado, pues él no es el demandado en el juicio de molestia, sino que el único demandado en dicho pleito es el comprador. $\mathrm{Al}$ respecto se revisarán los distintos argumentos para sustentar ambas posturas, aunque desde ya señalamos que convencen más aquellos que tienden a aceptar la posibilidad de que el tradente pueda alegarla.

i) En la redacción del art. 2493 del $C C$, Andrés Bello se inspiró en el art. 2225 del Code, que permitía que toda persona que tuviera interés en la prescripción de un tercero pudiera alegarla:

"Les créanciers, ou toute autre personne, ayant intérêt à ce que la prescription soit acquise, peuvent l'opposer, encore que le débiteur ou le propriétaire y renonce". ("Los acreedores, o cualquier otra persona con interés en la prescripción cumplida puede alegarla, aunque el deudor o el propietario la renuncie") [traducción libre] ${ }^{18}$.

Analizando esta cuestión, Ramón Domínguez señala que las reglas francesas e italianas

"se justifican plenamente, porque si el sujeto pasivo de la obligación es el primer interesado en la prescripción, no es siempre el único, y pueden existir terceros a quienes la inercia del deudor perjudique, de forma que resulta lógico que se les reconozca legitimación para alegarla. Y cabe observar que tanto en el código francés como en el italiano reconocen a esos terceros -entre ellos a los acreedoresuna legitimación directa y propia para la alegación"19.

$\mathrm{Al}$ respecto, refiere el mismo autor que la adecuada aplicación de esta cuestión no es una simple extrapolación de la acción oblicua o subrogatoria que el Código de Napoleón confiere a los acreedores de un modo general, sino de un derecho propio que no se ejerce por y en lugar del deudor, siendo más propiamente una legitimación alternativa conferida que se confiere al tercero. Por ello, abunda Ramón Domínguez, la norma versa sobre todo el que tenga interés en que la prescripción opere, ya sean terceros garantes, el vendedor obligado a la garantía de la evicción, el que

${ }^{18}$ El Código Civilitaliano de 1865 tenía una norma similar en su art. 2112, pues también fue influenciado por el Code: "Los acreedores ó cualquier otra persona interesada en hacer valer la prescripción, pueden oponerla aunque el deudor ó propietario renuncien á ella".

${ }^{19}$ Domínguez (2009), p. 90. 
ha adquirido la cosa existiendo antes un contrato nulo entre su vendedor y antecesor de este y otros, por lo que no se circunscribe exclusivamente al deudor negligente ${ }^{20}$.

Esta cuestión podría dar pie a que cualquiera pudiera alegar la prescripción en nuestro ordenamiento. Si bien la redacción del art. 2493 del $C C$ tiene una clara inspiración francesa, su texto no es tan explícito como la regla que le sirvió de base.

Por otra parte, la reglamentación del $C C$ nacional carece del complemento normativo que existe en el ordenamiento francés, en el cual se estatuye como regla general el permitir a terceros ejercer derechos ajenos en beneficio propio o de su titular. En el Code se estableció como regla general que el acreedor podía ejercer las acciones de su deudor para mantener o aumentar su patrimonio, y también para reclamar por los actos que intentaran defraudarlo, en su art. 1166:

"Néanmoins, les créanciers peuvent exercer tous les droits et actions de leur débiteur, à l'exception de ceux qui sont exclusivement attachés à la personne". ("Sin embargo, los acreedores pueden ejercer todos los derechos y acciones de su deudor, con excepción de los que están exclusivamente vinculados a la persona”) [traducción libre];

y en su art. 1167:

"Ils peuvent aussi, en leur nom personnel, attaquer les actes faits par leur débiteur en fraude de leurs droits. Ils doivent néanmoins, quant à leurs droits énoncés au titre Des successions et au titre $D u$ contrat de mariage et des régimes matrimoniaux, se conformer aux règles qui y sont prescrites". ("También pueden, en su propio nombre, impugnar los actos realizados por su deudor en fraude de sus derechos. No obstante, con respecto a sus derechos bajo el título Bienes y bajo el título Contrato de matrimonio y regímenes matrimoniales, deberán cumplir con las normas que en él se establecen") [traducción libre].

Pero en la reglamentación nacional no existen normas de este tipo, sino que solo hay hipótesis excepcionales que permiten a terceros ejercer derechos ajenos, y están reguladas bajo la lógica del pago por subrogación (arts. 1608 al 1613 del $C C$ ) y en relación

${ }^{20}$ Domínguez (2009), pp. 90-91. 
con la prelación de créditos (art. 2466 del $C C$ ), por lo que solo pueden aplicarse para los casos expresamente establecido ${ }^{21}$. Además, como toda excepción, debe interpretarse restrictivamente.

Sin perjuicio de lo referido, Ramón Domínguez se pronuncia a favor de que el vendedor citado de evicción pueda alegar la prescripción, aun cuando lo haga respecto de la prescripción extintiva, pues la lógica argumentativa es analogable, señalando:

"nos parece evidente que algunos supuestos (de terceros para alegar la prescripción respecto del deudor) habrán de ser admitidos. Así, el vendedor obligado al saneamiento de evicción debería entenderse autorizado para alegar la prescripción de alguna obligación del deudor, si ella permite la adecuada defensa de éste a que está obligado" 22 .

ii) Por otro lado, la única hipótesis contenida en el ordenamiento jurídico, relativa a la posibilidad expresa de que un tercero pueda oponer una prescripción ajena, tiene relación con el fiador, en relación con que este puede alegar la liberación de la deuda que se le pretende cobrar, aun cuando el deudor principal la haya renunciado, según dispone el art. 2496 del CC: "El fiador podrá oponer al acreedor la prescripción renunciada por el principal deudor".

Pero la justificación de esta norma está en que el fiador no es el deudor directo, sino subsidiario, por lo que si el fiado pudo librarse de la deuda y no lo hizo, haciendo que la obligación recayera sobre el fiador, es de entera justicia que este no sea arrastrado por la liberalidad del deudor principal, circunstancia que no se da en la relación entre el vendedor y el comprador, al no obedecer a la misma lógica, por lo que se entiende que no puede extrapolarse dicha circunstancia para excluir a la prescripción de entre las cuestiones que puede alegar el vendedor.

iii) A su vez, el art. 1839 del $C C$ dispone: "el vendedor es obligado a sanear al comprador todas las evicciones que tengan una causa anterior a la venta", estableciendo como regla general la responsabilidad del vendedor por todas las evicciones cuya causa sea anterior a la venta, señalando, además, que, por regla general, podrá librarse de esta responsabilidad "en cuanto se haya estipulado lo (1987).

${ }^{21}$ A favor de una aplicación general de la acción subrogatoria se manifiesta AlCALDE

${ }^{22}$ Domínguez (2009), p. 91. 
contrario", requiriéndose al efecto un pacto con su adquirente.

Por ello, si la ley hace responsable al vendedor, sin distinguir si el comprador opuso o no las excepciones o defensas "suyas", la propia ley debe darle todos los medios defensivos para que, en definitiva, no se verifique la evicción, por lo que debe permitírsele alegarla.

iv) Otro punto de vista para analizar esta cuestión emana de la lógica del inc. tercero del art. 1843 del $C C$, que señala que las excepciones o defensas mínimas que debe oponer el comprador son las "suyas", desmarcándose de la distinción relativamente usual que el $C C$ hace, dividiendo las excepciones en reales y personales ${ }^{23}$.

La norma no razona sobre esta distinción, pues nada justifica que la ley libere de responsabilidad al vendedor si el comprador no opuso alguna excepción real o personal, sino que entendemos que la norma se estructura sobre la base de que hay ciertas excepciones que solo puede oponerlas el comprador, y que por ello se le sanciona en caso de no oponerlas (inc. tercero art. 1843 del $C C$.

Sobre este punto, es importante considerar que en el Proyecto de Código Civil de 1846-1847, el inc. primero del art. 352 -art. 1843 actual-, señalaba que en caso de no comparecer, el vendedor sería responsable de la evicción

"a menos que el comprador haya dejado de oponer alguna defensa o excepción suya, como la de prescripción, i por ello fuere evicta la cosa",

señalando expresamente que una de aquellas excepciones "suyas" del comprador era la prescripción, cuestión que, si bien se eliminó, ilustra cuáles alegaciones Andrés Bello entendía que eran propias del comprador, y siendo propia del adquirente, es él quien

${ }^{23}$ Manuel Somarriva señala: "de los artículos 1520 y 2354 se deduce la clasificación de las excepciones en reales y personales. Las reales, como las denomina el artículo 2354, o las que resultan de la naturaleza de la obligación, como las llama el artículo 1520, son aquellas que dicen relación con la obligación misma, sin tomarse en consideración la situación de las partes. Las personales, por el contrario, se relacionan con la situación o calidad particular que tiene el deudor en la obligación. Nuestro Código ha considerado dentro de las excepciones reales tanto las que emanan de la naturaleza de la obligación, como las comunes que señala el Código francés, entre las cuales se comprenden aquéllas que se producen con posterioridad al nacimiento de la obligación y que pueden ser alegadas por cualquier deudor”. SOMARRIVA (1981), p. 69. 
es llamado a alegarla ${ }^{24}$, pero, en definitiva, optó por modificar el texto y eliminar la referencia a la prescripción.

v) Otro punto de vista sobre esta cuestión emana del art. 2495 del $C C$, que señala que solo puede renunciar a la prescripción quien puede enajenar.

Esta renuncia equivale a disponer del derecho ganado por prescripción ${ }^{25}$, de forma tal que a contrario sensu, para alegarla también sería necesario disponer del derecho cuya prescripción se ha cumplido, y el único que puede disponer del derecho de fondo que se discute es el comprador demandado, pues él es el único sujeto pasivo de la pretensión.

Esta cuestión, además, se complementa con el hecho de que la declaración de usucapión tiene como efecto que un bien ingrese al patrimonio del beneficiado, se requiere necesariamente que esa persona manifieste su voluntad en este sentido, tal como señala Daniel Peñailillo al revisar la voluntad unilateral como fuente de las obligaciones:

"ha de tenerse presente la afirmación, casi axiomática, de que nadie puede adquirir derechos (patrimoniales) contra su voluntad, y ni siquiera sin ella" 26 ,

por lo que la usucapión requiere necesariamente la voluntad del beneficiado, que en este caso es el comprador demandado.

Pero al respecto, si bien nadie puede adquirir derechos patrimoniales sin su voluntad, es claro que el comprador demandado ya manifestó que quería ingresar el bien a su patrimonio en el momento que celebró la compraventa con el vendedor, por lo que, aun cuando el demandado no alegue por sí mismo la usucapión $\mathrm{y}$, en consecuencia, nada diga respecto de que quiere incorporar dicho bien a su patrimonio por esa vía, esto es innecesario, porque él entendía que la cosa ya era suya, siendo ese, precisamente, el fundamento por el cual citó de evicción a su tradente.

vi) Por otro lado, si bien del art. 2493 del $C C$ se desprende que la prescripción deba ser alegada, la norma dispone: "el que quiera aprovecharse de la prescripción debe alegarla", cuestión que no excluye necesariamente al vendedor, quien al alegarla y lograr que se desestime el juicio de molestia, se "aprovechará" de ella, dado

${ }^{24}$ Véase Bello (1887), tomo XI, pp. 502-505.

${ }^{25}$ Abeliuk (2008), tomo II, p. 1195.

${ }^{26}$ Peñailillo (1999), p. 9. 
que rechazándose la demanda y evitándose la evicción, por regla general no podrá serle reclamada ningún tipo de responsabilidad, cuestión que, sin duda alguna, le "aprovecha", según el decir de la regla precitada.

vii) Desde otra óptica, la lógica del art. 2493 del $C C$ está en directa afinidad con la del art. 1844 del mismo cuerpo normativo, en virtud de la cual el vendedor pasa a ser formalmente el demandado del pleito, por lo que bajo este entendimiento, si el vendedor comparece, actuará "como si" fuera el demandado, por lo que podrá oponer todas las excepciones que podría oponer el comprador, pues tal dimensión no lo excluye.

viii)Por último, y desde el aspecto histórico, con toda seguridad esta norma se inspiró en la Partida $V$, título v, ley 36, pues tiene la misma lógica que la regulación de Andrés Bello, en el sentido de que el vendedor será, por regla general, responsable de la evicción, pero en su punto séptimo, hace referencia a la usucapión:

"Por cuales razones no es obligado el vendedor de hacer seguro el objeto al comprador. El vendedor, conforme hemos dicho está obligado de hacer segura al comprador la cosa que le vende, y si no de regresarle el costo con todos los daños y los perjuicios que le llegaron por tanto si no se la ampara; pero existen casos en que no sería así: El séptimo, así la cosa que compró cuando se la demandaron en el juicio, tenía tanto tiempo que era poseedor de ella que la podría amparar según derecho por tal defensión, si la pusiera ante sí y no la puso"27.

Siendo que la regla general bajo esa norma es que el vendedor es responsable de la evicción, la excepción -en lo que nos interesa-, tiene relación con el hecho de que pudiendo el comprador oponer la usucapión, no lo hizo, sin distinguir si el vendedor había o no comparecido al pleito, por lo que la norma entiende que el comprador es el llamado a alegarla, sin dar ningún indicio de que pudiera oponer dicha excepción el vendedor, pero como es claro, si bien la norma de Las Partidas inspiró esta regulación, parece que el texto final se aleja de esa lógica.

\section{Reconocimiento jurisprudencial}

No existe ningún caso en el que el demandante haya controvertido la legitimación del vendedor citado de evicción para alegar esta prescrip-

${ }^{27}$ Alfonso el Sabio (2009). 
ción, ya sea que la haya opuesto como excepción o en virtud de demanda reconvencional ${ }^{28}$; ni tampoco que algún tribunal de motu proprio haya analizado este punto.

Pero tácitamente, la jurisprudencia admite de forma absolutamente unánime que el vendedor citado de evicción pueda alegar la prescripción adquisitiva, ya sea como excepción o como acción en una demanda reconvencional al efecto, pues en caso de alegarse la usucapión y verificarse sus presupuestos, el tribunal simplemente analizará el fondo de esta cuestión, pasando a ser irrelevante para su acogimiento o rechazo si la alega el comprador o el vendedor, fallándose indistintamente sin atender a quien hizo la alegación ${ }^{29}$. En un caso, de los mucho que existen, la Corte Suprema falló esta cuestión al acoger un recurso de casación en el fondo y declarar la prescripción alegada exclusivamente por el citado de evicción por vía reconvencional, simplemente porque se verificaban los supuestos para acogerla ${ }^{30}$.

${ }^{28}$ La mayoría de la doctrina entiende que la prescripción adquisitiva no solo debe ser alegada, sino que debe ser declarada judicialmente, lo cual se hacer por medio de una pretensión deducida al efecto -Peñailillo (2019), p. 1035 y ss.; Domínguez (2009), pp. 74-75, entre muchos otros y, asimismo, ha resuelto la jurisprudencia, tanto por parte de la Corte Suprema -María Serrano Troncoso con Jaime Aravena Leal (2014) como por distintas Corte de Apelaciones- María Serrano Troncoso con Jaime Aravena Leal (2014), Corte de Apelaciones de San Miguel.

${ }^{29}$ En este sentido, lo que ocurre en estos casos es que el tribunal no cuestiona quién dedujo el recurso interpuesto, sino que simplemente ve el fondo de la controversia, en términos que no existe una pronunciamiento sobre la legitimación o titularidad del recurrente, cuestión que se subentiende válida al no existir cuestionamientos de este tipo. Esto ocurre en numerosos fallos, en los que solo existe un pronunciamiento sobre el mérito del recurso interpuesto, sin cuestionar la titularidad del recurrente para recurrir, tal como ha resuelto la Corte Suprema, entre otras causas, en María Serrano Troncoso con Jaime Aravena Leal (2014); Matías Daneri Bascuñán con Sociedad Agrícola Soagromayor (2012); Alfredo Mateluna Aristizábal, con Sociedad Inmobiliaria e Inversiones Las Perdices Ltda. (2011); Sociedad Inmobiliaria del Puerto Ltda. con José Miguel Tebar Martínez (2011); Rosemarie Elizabeth Jeffery Peet con José Agustín Soto Silva y otros (2011a); Agrícola Paula Limitada con Rolando Klagges (2011); Elba Fernández Peña con Salvador Covarrubias Rodríguez (2007); Carlos González Echazu con Ramón Aranzasti Martínez (2007); Manuel Briones Cancino con Víctor Fuentes Tejos (2004); Belfor Estrada Medina con Transportadora Río Cisne (2003), entre muchas otras.

De igual forma, cuando no se verifiquen los presupuestos fácticos exigidos por la ley para declarar la usucapión, igualmente se ha fallado sobre el fondo, como resolvió el juzgado de letras de Yungay, donde el citado de evicción dedujo demanda reivindicatoria de prescripción adquisitiva, pero fue rechazada porque no demandaron reconvencionalmente a todos los comuneros. Juzgado civil de Yungay, Monjes y otros con Arriagada y otros (2017).

30 "Que se revoca, igualmente la sentencia antes individualizada, en cuanto rechaza las demandas reconvencionales interpuestas por los citados de evicción en el primer 
Pero como se ha dicho, esta unanimidad jurisprudencial viene dada, en primer término, por el hecho de que el vendedor instará por todos los medios a que se rechace la demanda deducida contra el comprador, alegando la prescripción como excepción al contestar y deduciendo demanda reconvencional, sin cuestionarse si está o no habilitado para alegarla y, además, por el hecho de que en general el demandante no controvierte la legitimación para oponer esta excepción, por lo que el tribunal no se ve obligado a analizar este punto; ni tampoco, como se ha señalado, lo analiza de oficio el sentenciador, de forma tal que estamos ante una unanimidad jurisprudencial que se basa en una mera práctica judicial, sin existir un análisis más profundo al respecto.

A su vez, en contextos distintos de la citación de evicción han sido muy pocos los fallos que se han pronunciado sobre la titularidad de un tercero para alegar la usucapión en favor de otro, y que podrían servir para orientar lo que se está analizando, y uno de estos casos se dio en el marco de una ejecución, en la que se dedujo una tercería respecto del bien embargado, y en la cual el ejecutante alegó oblicuamente la prescripción adquisitiva respecto del ejecutado, cuestión que beneficiaba su ejecución, pues mantenía el bien en el patrimonio del ejecutado. La alegación del ejecutante fue rechazada por la Corte Suprema, sustentado en que para que un tercero pudiera alegar una usucapión ajena, debía existir norma expresa que se lo permitiera ${ }^{31}$.

otrosí de fojas 170, y en el segundo otrosí de fojas 218, por la Sociedad Agrícola Río Cisnes Limitada, y en su lugar se declara que la demandada ha adquirido el predio reivindicado por prescripción adquisitiva, sin que tenga importancia para los efectos de este juicio determinar si ella fue ordinaria o extraordinaria”. Belfor Estrada Medina con Transportadora Río Cisne (2003).

${ }^{31}$ Estévez con López (1938); Rioseco (1994), p. 17: “6 Que se impone, finalmente, el rechazo de la tercera causal, consistente en la contravención a lo prevenido en los artículos 2492, 2498 y 2511 del Código Civil, pues se limitan, o a definir la prescripción, o a enunciar lo que es apto para ser adquirido por medio de ella, a virtud de la posesión, o a determinar el lapso de tiempo indispensable para ganar, por la que se califica de extraordinaria, el dominio de las cosas corporales o incorporales que se hallan en el comercio humano, sin que confieran autorización al acreedor para alegar, en su beneficio, la prescripción que favorezca al deudor, ni le den la propiedad del inmueble que, en razón de su crédito, se le haya hipotecado; $7^{\circ}$ Que, de las notas colocadas por don Andrés Bello en artículos de su Proyecto Inédito de Código Civil, relacionadas con la materia que se trata, se desprende que, principalmente, se tuvo presente, al redactarlos, el Código Civil francés, Código que, en su artículo 2225, permite oponer la prescripción a los acreedores o a cualquiera otro interesado en hacerla valer, aunque el deudor o propietario la renuncie; $8^{\circ}$ Que ni ese artículo, ni los signados en el propio cuerpo de leyes con los números 1166 y 1167, que otorgan a los acreedores, por un lado la facultad de ejercer todas las acciones de sus deudores, salvo las ligadas a la persona de los mismos, y, por otro, la de atacar, en su nombre personal, los actos ejecutados por aquellos en fraude de sus derechos, fueron 
Por su parte, el voto de minoría del mismo fallo, que estaba por permitir que el ejecutante alegara la usucapión, entendió que tanto el ejecutante como el ejecutado son codemandados respecto del tercerista y, sobre la base de dicha calidad, se razonó que cualquiera de las partes puede defender el dominio cuestionado en la tercería, permitiendo, incluso, que el ejecutante oponga las defensas y excepciones, que son propias del ejecutado $^{32}$, cuestión que podría extrapolarse a la hipótesis que se analiza en razón de que en virtud del art. $1844 \mathrm{del} C C$, el vendedor debe comportarse como si fuera demandado, y en dicha calidad, podría alegar la usucapión.

Sobre el punto, se decantó el permitir al vendedor alegar la usucapión, y ello basado, principalmente, en que si el art. 1839 del $C C$ hará responsable al vendedor de "sanear al comprador todas las evicciones que tengan una causa anterior a la venta", es indispensable que la ley le de todos los medios defensivos para que, en definitiva, no se verifique la evicción, pues carecería de sentido que si el derecho sustantivo lo hiciera responsable bajo esta circunstancia, el derecho adjetivo no le diera las herramientas para prevenir esta responsabilidad, pues de lo contrario estaría obligado a lo imposible, lo que es del todo inadmisible.

Por lo demás, se entiende que no es obstáculo para esta cuestión que el art. 2493 del $C C$ no sea tan explícito como la norma que la inspiró -el art. 2225 del Code-, dado que, si bien no existe un complemento normativo

incorporados en nuestra legislación, y al haber, en esta, disposiciones sustantivas o adjetivas que consientan ejercitar las acciones o deducir las excepciones del sujeto que ha contraído compromisos garantidos con hipoteca, a fin de asegurar que sean satisfechos, no sería del caso hacer reflexiones a su respecto, por cuanto lo impediría la norma consagrada en el art. 494 del Código de Enjuiciamiento Civil, en orden a que, aun cuando en el progreso del recurso se descubra una nueva causa en que hubiera podido fundarse, la sentencia recaerá únicamente sobre las alegadas en tiempo y forma".

${ }^{32}$ Estévez con López (1938), voto de minoría: "Es inconcuso en nuestra legislación positiva, el derecho del acreedor ejecutante para oponer al tercerista que reclama dominio sobre el bien embargado, todas las excepciones que pudiera oponer el ejecutado para sostener ese dominio, toda vez que el Código Procesal Civil inviste al ejecutante como legítimo contradictor del tercerista en esa discusión, al instituirlo como parte principal demandada en la sustanciación de la tercería. Y si al demandado le incumbe oponer excepciones perentorias contra la demanda, claro es, entonces, que corresponde al ejecutante sostener el dominio del ejecutado, y lógicamente tendrá que hacerlo valiéndose de los mismos medios legales como éste podría defenderse, esto es, invocando modos de adquirir y títulos propios del ejecutado, capaces de constituir excepciones, ya que para eso llama la ley a intervenir forzadamente en la tercería al ejecutante: para que en resguardo de su derecho e interés salvo las omisiones o soluciones en que incurra el ejecutado al defenderse, el cual, bien se sabe, puede llegar al extremo de reconocer el dominio del tercerista. Y no hay para qué hacer notar que, en último término, el modo más eficaz de resguardar un dominio es la alegación de la prescripción adquisitiva por parte del titular, del dueño". 
como en la reglamentación napoleónica, se entiende que la particular naturaleza de la intervención del vendedor a la luz de lo dispuesto en el art. 1844 del $C C$ le permitiría reclamar la usucapión a nombre del adquirente.

Además de ello, el art. 2493 del $C C$, contenido en el párrafo que es común a ambos tipos de prescripción, señala: "quien quiera aprovecharse de la prescripción debe alegarla", cuestión que como se refirió, no puede excluir de forma alguna al tradente, dado que alegar la usucapión le "aprovechará", pues de acogerse la alegación y evitar la evicción, no será condenado a resarcir al adquirente, todas cuestiones que llevan a decantar por admitir de forma amplia que el vendedor pueda alegar la usucapión a nombre del comprador.

\section{En relación a la prescripción extintiva, ¿puede el vendedor citado de evicción alegarla en favor del comprador?}

Atendida la naturaleza de la pretensión que el vendedor es llamado a rechazar en el contexto del juicio de molestia, las posibilidades de alegar la prescripción liberatoria se reducen considerablemente. Las hipótesis más usuales serán los casos contemplados en los arts. 898 y 900 del $C C$, que permiten al actor ejercer la demanda reivindicatoria en contra de quien enajenó una cosa cuya persecución sea difícil o imposible, para que le restituya lo que recibió por ella y le resarza todos los perjuicios, cuestión que algunos denominan reivindicatoria "ficta" 33 .

Pero en estos casos, como lo que se reclama no es la cosa sino dinero -precisamente porque la cosa fue enajenada-, se plantea la discusión de si la reclamación es propiamente una pretensión personal o real ${ }^{34}$; y entendiéndose que la demanda es personal, aplicarían las reglas generales de

${ }^{33} \mathrm{Al}$ respecto, Fernando Atria señala: "la acción reivindicatoria ficta tiene dos modalidades: la del art. 898 y la del art. 900. En ambos casos se trata de una acción que ya no es real, sino personal, como consecuencia de que el ejercicio de la acción real de dominio se ha hecho fútil. En el caso del artículo 898, si el poseedor ha dejado de serlo de buena fe, la acción reivindicatoria ficta tiene por objeto el valor efectivamente recibido por el poseedor a cambio de la cosa; si dejó de poseer de mala fe, la indemnización de todo perjuicio. La acción del art. 898 supone que el poseedor ha enajenado la cosa. Dicha enajenación (a título oneroso) es indispensable en el caso del que enajenó de buena fe, porque marca los límites de su responsabilidad. Pero en el caso del que enajenó de mala fe no es necesaria, y por eso es mejor la formulación del art. 900: en este caso basta que el poseedor haya 'dejado de poseer', con enajenación o sin ella, porque su responsabilidad no tiene límites, y alcanza a todos los daños causados. Atria (2017), p. 169. Así, también, la jurisprudencia le da con frecuencia dicha denominación - Rodrigo Fabres Zavala con Comercial de Valores S. A. (2015); Eduardo Ruiz Ruiz con Kaufmann S.A. y otros (2015), entre otros.

${ }^{34}$ Véase Vodanovic (1993), tomo II, p. 287. 
este instituto, de forma tal que habiendo transcurrido más de cinco años entre la enajenación de la cosa y la reclamación del tercero, es posible alegar la prescripción.

En estos casos no se presentan las mismas dudas que respecto de la usucapión, pues en esta los cuestionamientos vienen dados por el hecho de que la reclamación exigiría pedir algo directamente a favor del comprador, pero al oponer la prescripción extintiva, lo que se hace es denunciar que la acción misma estaría prescrita, oponiéndose directamente a la pretensión interpuesta, que es precisamente lo que los arts. 1843 y 1844 del $C C$ lo llaman a hacer.

A su vez, en hipótesis distintas, solo en una ocasión fue cuestionada la legitimación del citado de evicción para alegar la prescripción extintiva, específicamente respecto de la prescripción especial contenida en el art. 16 del DL 2695, de 1979, frente a una demanda reivindicatoria, siendo rechazada la oposición y acogida la excepción opuesta, desestimándose, en definitiva, la pretensión deducida.

En este caso se dedujo una demanda reivindicatoria que fue desestimada en primera y segunda instancia al acogerse la prescripción extintiva especial contenida en el art. 16 del DL 2695 de 1979, en relación con los arts. 26 y 28 del mismo decreto, y que fue opuesta por el vendedor citado de evicción. Al respecto, el actor recurrió ante la Corte Suprema alegando error de derecho, fundado en la vulneración de los arts. 1837 y 1844 del $C C$, al admitirse a tramitación y acogerse esta prescripción opuesta por el citado de evicción y no por el demandado, pues en concepto del recurrente, solo podía alegar esa defensa el comprador demandado, no el vendedor citado de evicción.

El fallo de la Corte Suprema sintetizó la causal alegada por el recurrente de la siguiente manera:

"En primer lugar acusa que los jueces vulneran los artículos 1837 y 1844 del código sustantivo por errónea aplicación, y el 2493 de ese mismo cuerpo legal por falta de aplicación al admitir que la citada de evicción opusiera la excepción de prescripción extintiva de la acción ya que, en opinión de quien recurre, tal excepción sólo podía ser invocada por el adquirente del inmueble, único que puede aprovecharse de la referida prescripción, lo que resulta lógico si se considera que de conformidad al artículo 2495 del mismo texto legal, la prescripción puede ser renunciada por su legitimado activo y que de acuerdo al mencionado artículo 1843 se exime de responsabilidad al vendedor citado de evicción que no comparece si el comprador ha dejado de oponer alguna defensa o excepción suya y por ello fuera evicta la cosa, postulando la actora que de 
no haberse vulnerado tales disposiciones se habría rechazado la antedicha defensa, acogiéndose la demanda de reivindicación de conformidad a los artículos 889, 700, 724 y 582 del Código Civil, ya que consta en autos su condición de poseedora inscrita y dueña del inmueble reclamado" 35 .

$\mathrm{Al}$ respecto, la Corte Suprema desestimó la nulidad sustancial alegada, señalando:

"por último, tampoco se aprecia que los sentenciadores hayan quebrantado los artículos 1837, 1844 y 2493 del código sustantivo al admitir que la citada de evicción opusiera la excepción de prescripción extintiva de la acción cuyo acogimiento conllevó a desestimar la acción reivindicatoria pues Inmobiliaria Martabid Limitada compareció al proceso asumiendo la condición de parte principal demandada en el juicio, calidad en la que bien pudo oponer todas las defensas necesarias para amparar a su comprador en el dominio y posesión pacífica del inmueble disputado a fin de hacer cesar toda turbación o embarazo sobre el mismo y, entre ellas, la prescripción extintiva contemplada en la norma especial del artículo 16 del D.L. N 2.695, disposición que constituye una excepción a la regla general del artículo 2517 del Código Civil y cuya aplicación resulta procedente al caso en estudio, como han concluido los sentenciadores" ${ }^{\prime 3}$,

razonando así sobre la base de que de acuerdo con el art. 1844 del $C C$, el vendedor tendría la calidad de parte del proceso y, por ello, podría alegar la excepción.

Por su parte, en el fallo de segunda instancia dictado en esta misma causa, la Corte de Apelaciones de Concepción se basó en el mismo fundamento, aunque fue más directa en su raciocinio, al resolver:

"citada de evicción Inmobiliaria Martabid Limitada al comparecer al proceso ha pasado a ser parte principal demandada en el juicio, pues 'se seguirá contra él solo la demanda' [art. 1844 del Código Civil y el objeto de su comparecencia, conforme a lo dispuesto en el artículo 1837 del Código Civil, es la de amparar a su comprador en el dominio y posesión pacífica del inmueble de autos,

${ }^{35}$ Portuaria Cabo Froward S.A. con Servicio de Vivienda y Urbanismo Región del Bio Bío (2017).

${ }^{36}$ Ibid. 
defendiéndolo con la finalidad de hacer cesar toda turbación o embarazo sobre el bien raíz como pretende la actora y es así como ha opuesto la excepción de prescripción extintiva y que acogió la sentencia en alzada" ${ }^{37}$.

Estos fallos son sumamente interesantes, porque es la primera vez que se cuestiona, en el contexto de una citación de evicción, la legitimación del vendedor para oponer la prescripción, y como se refirió, tanto la Corte Suprema como la Corte de Apelaciones razonaron sobre la base de la particular naturaleza de la intervención del vendedor conforme dispone el art. 1844 del $C C$, la que habilitaría al vendedor para alegar la prescripción. En otro caso, sin relación con la citación de evicción, la Corte Suprema tuvo oportunidad de pronunciarse sobre la legitimación de un tercero para alegar la prescripción de una obligación ajena. Acogiendo un recurso de casación en el fondo, el máximo tribunal señaló que el propietario de un bien hipotecado por una obligación ajena podía alegar la prescripción de la deuda para alzar el gravamen sobre su propiedad, reconociéndole legitimación propia por tener un interés directo en el ejercicio de la pretensión extintiva $^{38}$, cuestión que se condice con el interés que tiene el vendedor

${ }^{37}$ Portuaria Cabo Froward S.A. con Servicio de Vivienda y Urbanismo Región del Bio Bío (2015).

${ }^{38}$ Lucia de Lourdes Mena Mundt con Corfo (2016), sentencia de reemplazo: “Tercero: Que, en el caso de autos, la actora es poseedora de derechos de aguas hipotecados para el cumplimiento de una obligación principal que emana de un contrato de apertura de crédito a un tercero y, por consiguiente no es deudora de la sociedad acreedora ni nunca lo ha sido. Ahora bien, su interés, desde luego, es obtener que se declare extinguida su obligación de carácter accesoria para así alzar la hipoteca pero, para ello, es menester que previamente se declare la extinción de la obligación principal. Lo anterior requeriría necesariamente el emplazamiento del deudor, gestión que se torna imposible en la especie, en tanto éste fue declarado en quiebra por sentencia de 10 de mayo del año 2004, sin que la acreedora haya verificado el crédito en dicho procedimiento concursal. Cuarto: Que, en este escenario, no resulta posible exigir a la propietaria del bien hipotecado el ejercicio de alguna vía distinta a objeto de liberarlo del gravamen, debiendo, por tanto, reconocerse su legítimo interés en el ejercicio de la acción de prescripción extintiva que beneficia al deudor principal, en tanto es la única que posee al efecto. Dicho interés, por tanto, permite que la demandante goce de la legitimación activa para deducir las acciones objeto de estos antecedentes".

En la misma causa, también es interesante el fallo de casación: "Duodécimo: Que, en las condiciones expresadas resulta innegable el interés de la dueña del bien hipotecado en la declaración de prescripción de las acciones destinadas al cumplimiento de las obligaciones emanadas del contrato, considerando que la situación jurídica que afecta al deudor principal torna imposible para él ejercer cualquier acción que tenga como consecuencia la liberación del inmueble. Sobre la posibilidad de alegación de la prescripción de la acción de cobro por parte de quien no es el sujeto pasivo de la obligación, ya se ha pronunciado la doctrina, señalando que 'pueden existir terceros a quienes la inercia del 
citado de evicción para que se rechace la demanda, lo que le habilitaría a alegarla. A su vez, el voto de minoría del mismo fallo entendió que no existe legitimación propia del dueño del bien hipotecado para alegar la prescripción de la deuda, pues es un tercero ajeno al contrato de crédito ${ }^{39}$.

De esta forma, en relación con la legitimación del vendedor para oponer la prescripción extintiva, se entiende que no existen los mismos cuestionamientos que respecto de la usucapión, cuestión que se da principalmente porque el vendedor se está propiamente defendiendo de la pretensión deducida en contra del comprador, que es precisamente lo que los arts. 1843 y 1844 del $C C$ lo llaman a hacer, y lo que se complementa con la particular naturaleza en virtud de la cual el tradente comparece al pleito, en términos que se sigue contra él solo la demanda interpuesta, según dispone el art. 1844 del $C C$, lo que le habilita al efecto a poder oponer la excepción en comento.

\section{Conclusiones}

1. La particular naturaleza de la intervención del vendedor citado de evicción, conforme dispone el art. $1844 \mathrm{del} C C$, lleva a preguntarse si puede o no oponer la prescripción adquisitiva, extintiva o ambas en beneficio del comprador en el juicio de molestia.

2. En relación con la usucapión, si bien la jurisprudencia es unánime para dar una amplia titularidad al vendedor para alegar la prescripción adquisitiva, ya sea como defensa por medio de una

deudor perjudique, de forma que resulta lógico que se les reconozca legitimación para alegarla' (Ramón Domínguez Águila. La Prescripción Extintiva. Editorial Jurídica de Chile. Año 2004, página 90). Agrega el autor que no se trata de una acción ejercida por y en lugar del deudor, sino de un derecho propio, de una legitimación alternativa conferida al tercero. En efecto, debe concluirse que la demandante tiene un claro interés en obtener la declaración de prescripción de la obligación principal pues, en los hechos, se torna en la única manera que tiene de lograr que se declare la de su propia obligación hipotecaria”. Lucia de Lourdes Mena Mundt con Corfo (2016).

39 "Que el principal argumento jurídico de la demandada para sostener su alegación de falta de legitimación de la actora que fue acogida por el fallo impugnado se funda en lo dispuesto por el artículo 1545 del Código Civil, que sólo vincula a quienes participaron del contrato o acuerdo de voluntades del que se generaron los derechos y obligaciones que constituyen su objeto. Precisamente en el motivo tercero de la sentencia atacada se hace constar que la actora es un tercero ajeno al contrato de apertura de crédito a que se refiere esta causa, de lo que surge que la pretensión medular ha sido ejercida por quien no es titular de la acción principal hecha valer, motivo básico por el cual la demanda ha sido desestimada". Lucia de Lourdes Mena Mundt con Corfo (2016), voto de minoría del fallo de casación. 
excepción, o en virtud de una demanda reconvencional deducida por el vendedor, ello viene dado porque jamás se ha cuestionado la titularidad del vendedor para reclamarla, por lo que se estima que debiera hacerse una revisión más profunda de esta cuestión.

3. Sin perjuicio de lo señalado, y más allá de la unanimidad jurisprudencial, se entiende que la balanza se inclina dogmáticamente hacia entender que el vendedor tiene amplia titularidad para reclamar la prescripción adquisitiva, dado que si la ley dispone que el tradente será por regla general responsable de la evicción que se verifique (art. 1839 del $C C$ ), es indispensable que se le den todas las herramientas necesarias para evitarlo, permitiéndosele, en consecuencia, reclamar la usucapión, pues en caso contrario, se lo obligaría a responder de una evicción respecto de la cual no tuvo oportunidad de desplegar una completa defensa, atentando contra consideraciones mínimas de justicia a su respecto.

4. En relación con la excepción extintiva, atendida la naturaleza de la pretensión que es llamado a rechazar en el contexto del juicio de molestia, las posibilidades de alegarla se reducen de forma importante, se entiende que igualmente el vendedor tendrá plenas facultades para oponer la excepción liberatoria, tal como se ha resuelto en los pocos casos en que ha sido controvertido, pues dicha excepción apunta directamente al rechazo de la pretensión, que es precisamente a lo que los arts. 1843 y $1844 \mathrm{del} C C$ le exigen al vendedor.

\section{Bibliografía CitADA}

Abeliuk Manasevich, René (2008). Las obligaciones. $5^{\text {a }}$ edición actualizada. Santiago: Editorial Jurídica de Chile, tomos I y II.

Alcalde Rodríguez, Enrique (1987). "La acción subrogatoria". Revista Chilena de Derecho, volumen 14, n. ${ }^{\circ}$ 2-3.

Alessandri Rodríguez, Arturo (2003). De la compraventa y de la promesa de venta, reimpresión. Santiago: Editorial Jurídica, tomo I, volumen II y tomo II, volumen I.

Alfonso el Sabio (2009). Las Siete Partidas de Alfonso el Sabio. Guadalajara: Colegio de Notarios del Estado de Jalisco.

Atria Lemaitre, Fernando (2017). "El sistema de acciones reales, parte especial: acción reivindicatoria, publiciana y del art. 915". Revista Ius et Praxis, año $23,{ }^{\circ}{ }^{\circ}$.

Bello LóPez, Andrés (1887). Obras completas de don Andrés Bello. Santiago: Dirección del Consejo de Instrucción Pública, tomo XI. 
Carnelutti, Francesco (1960). Instituciones del proceso civil. (trad.) de la $5^{\mathrm{a}}$ edición italiana por Santiago Sentis Melendo. Buenos Aires, Ediciones Jurídicas Europa-América, tomo I.

Carrasco Poblete, Jaime (2010). La rebeldía en los procesos civil y laboral. Santiago: Abeledo Perrot-LegalPublishing.

Casarino Viterbo, Mario (2005). Manual de derecho procesal (derecho procesal civil). Reimpresión de la $6^{\mathrm{a}}$ edición. Santiago: Editorial Jurídica, tomo VI.

Cortez Matcovich, Gonzalo (2014). "Segunda parte. La fase de discusión”, en Andrés Bordalí Salamanca, Gonzalo Cortez Matcovich y Diego Palomo. El juicio ordinario de mayor cuantía, procedimiento sumario y tutela cautelar. Santiago: Legal Publishing.

Couture, Eduardo José (2010). Fundamentos del derecho procesal civil. Cuarta reimpresión de la $4^{\mathrm{a}}$ edición. Buenos Aires: Euros Editores S.R.L.

De La Oliva Santos, Andrés (2005). Objeto del proceso y cosa juzgada en el proceso civil. Navarra: Aranzadi.

De la Oliva Santos, Andrés, Ignacio Diez-Picazo Gimenez y Jaime Vegas ToRRes (2012). Curso de Derecho Procesal Civil, I, parte general. Madrid: Centro de Estudios Ramón Areces.

Díez DuARTe, Raúl (1993). La compraventa en el código civil chileno. $2^{\text {a }}$ edición actualizada. Santiago: Editorial Jurídica Conosur.

76 Díez Duarte, Raúl (2009). La compraventa. Santiago: El Jurista.

Domínguez Águila, Ramón (2009). La prescripción extintiva. Doctrina y jurisprudencia. Reimpresión de la $1^{\mathrm{a}}$ edición. Barcelona: Signo.

Guasp Delgado, Jaime (1985). La pretensión procesal. Madrid: Civitas.

Maturana Miquel, Cristián (2009). "Disposiciones comunes a todo procedimiento". Separata. Santiago: Central de Fotocopias de la Facultad de Derecho de la Universidad de Chile.

Meza Barros, Ramón (2010). Manual de derecho civil. Fuentes de las obligaciones. Santiago: Editorial Jurídica de Chile, tomo I.

Ocaña Rodríguez, Antonio (1997). Partes y terceros en el proceso civil. Perspectiva jurisprudencial y práctica. Madrid: Editorial Colex.

Peñailillo Arévalo, Daniel (1999). "La declaración unilateral de voluntad como fuente de obligaciones". Revista de Derecho Universidad de Concepción, año 67, n. ${ }^{\circ} 206$.

Peñailillo Arévalo, Daniel (2019). Los bienes. La propiedad y otros derechos reales. $2^{a}$ edición. Santiago: Thomson Reuters.

Rioseco EnríQuez, Emilio (1994). La prescripción extintiva ante la jurisprudencia. Santiago: Editorial Jurídica de Chile.

Silva Hanisch, Maximiliano (2017). "La terminación anticipada del proceso por la desaparición sobrevenida del interés en el proceso civil chileno". Revista de Derecho de la Pontificia Universidad Católica de Valparaíso, año 2017, volumen 48, n. ${ }^{\circ}$. 
Serra Domínguez, Manuel (1969). Estudios de derecho procesal. Barcelona: Ediciones Ariel.

Sin AUTOR (1901). Actas de la comisión mista de senadores y diputados encargada de informar sobre los proyectos de códigos de procedimiento civil i criminal. Santiago: Imprenta Nacional.

Somarriva Undurraga, Manuel (1981). Tratado de las cauciones. Santiago: Contable Chilena Limitada Editores.

Stoenrel Maes, Carlos Alberto y Mario Muñoz Salazar (1961). Procedimiento civil (juicios especiales). Santiago: Editorial Jurídica de Chile.

Tapia Fernández, Isabel (2000). El objeto del proceso. Alegaciones. Sentencia. Cosa juzgada. Madrid: La Ley.

VAras S., Eduardo y Álvaro Vergara V. (1908). Esplicaciones de derecho civil. Segundo año. Tomadas en clase de don Luis Claro Solar. $2^{\text {a }}$ edición. Santiago: Imprenta, Litografía y Encuadernación Chile.

Vodanovic Haklicka, Antonio (1942). Curso de derecho civil. Fuente de las obligaciones, basado en las explicaciones de los profesores de la Universidad de Chile Arturo Alessandri Rodríguez y Manuel Somarriva Undurraga. Santiago: Editorial Nascimento, tomo IV

Vodanovic Haklica, Antonio (1993). Tratado de los derechos reales, basado en las explicaciones de los profesores de la Universidad de Chile Arturo Alessandri Rodríguez y Manuel Somarriva Undurraga. Santiago: Editorial Jurídica de Chile, tomo II.

WAch, Adolf (1979). Manual de derecho procesal civil. (trad.) Tomás A. Banzhaf. Buenos Aires: Ediciones Jurídicas Europa-América, tomo II.

\section{Normas citadas}

\section{Código Civil.}

\section{Código de Procedimiento Civil.}

Decreto ley n. ${ }^{\circ} 2695$ de 21 de julio de 1979, que fija normas para regularizar la posesión de la pequeña propiedad raíz y para la constitución del dominio sobre ella.

\section{Jurisprudencia citada}

Agrícola Paula Limitada con Rolando Klagges (2011): Corte Suprema, 12 de octubre de 2011, rol 9863-2010.

Arangua Cuadra, Sara Luisa con Arturo Ramírez y otro (1945): Corte de Apelaciones de Santiago, 29 de agosto de 1945, en RDJ, tomo XLIII, secc. $2^{\mathrm{a}}$, p. 65.

Barria Sánchez, Daniel y otro con Fisco de Chile y otros (2005): Corte de Apelaciones de Santiago, 10 de mayo de 2005, rol 3253-1995.

Briones Cancino, Manuel con Víctor Fuentes Tejos (2004): Corte Suprema, 12 de octubre de 2006, rol 2530-2004. 
Brosio Domingo, Simón con Erasmo Torres Viera (2000): Corte Suprema, 29 de septiembre de 2000, rol 4183-1999.

Brosio Domingo, Simón con Gustavo Pérez Jeria (2000): Corte Suprema, 26 de septiembre de 2000, rol 4064-1999.

Brosio Domingo, Simón con Manuel Díaz Peralta (2000): Corte Suprema, 27 de septiembre de 2000, rol 4184-1999.

Brosio, Domingo Simón con Manuel Antonio Díaz Peralta (1999): Corte de Apelaciones de Rancagua, 13 de octubre de 1999, rol 15028, WestLaw CL/ JUR/1929/1999.

Brosio Domingo, Simón con Oscar Caces Núñez y otro (2000): Corte Suprema, 27 de septiembre de 2000, rol 3931-1999.

Brosio Domingo, Simón con Silvia Peña Villar y otro (2000): Corte Suprema, 26 de septiembre de 2000, rol 4066-1999.

Daneri Bascuñán, Matías con Sociedad Agrícola Soagromayor (2010): Corte de Apelaciones de Talca, 17 de diciembre de 2010, rol 185-2010.

Daneri Bascuñán, Matías con Sociedad Agrícola Soagromayor (2012): Corte Suprema, 9 de mayo de 2012, rol 2398-2011.

Enrico, José con Aros, Antonio (1948): Corte de Apelaciones de Santiago, 28 de junio de 1948, en RDJ, tomo XLVI, secc. $2^{\circ}$, p. 25.

Estévez con López (1938): Corte Suprema, 25 de marzo de 1938, en $R D J$, tomo XXXV, sec. $1^{\mathrm{a}}$, p. 425.

Estrada Medina, Belfor con Transportadora Río Cisne (2003): Corte Suprema, 22 de mayo de 2003, rol 294-2002.

Fabres Zavala, Rodrigo con Comercial de Valores S. A. (2015): Corte Suprema, 5 de marzo de 2015, rol 28250-2014.

Fernández Peña, Elba con Salvador Covarrubias Rodríguez (2007): Corte Suprema, 11 de junio de 2007, rol 1992-2005.

González Echazu, Carlos con Ramón Aranzasti Martínez (2007): Corte Suprema, 23 de agosto de 2007, rol 4361-2006.

Gutiérrez, Carmen con Juan Antonio Pando (1873): Corte de Apelaciones de Santiago, 25 de junio de 1873, en GT, sentencia n. ${ }^{\circ} 1292$, p. 571.

Inmobiliaria El Tineo con Alicia del Carmen Rencoret Benavides (2015): Corte de Apelaciones de Valparaíso, 5 de junio de 2015, rol 635-2015.

Jeffery Peet, Rosemarie Elizabeth con José Agustín Soto Silva y otros (2009): Corte Suprema, 28 de mayo de 2009, rol 6252-2006.

Jeffery Peet, Rosemarie Elizabeth con José Agustín Soto Silva y otros (2011): Corte Suprema, 27 de mayo de 2011, rol 5460-2009.

Mateluna Aristizábal, Alfredo con Sociedad Inmobiliaria e Inversiones Las Perdices Ltda. (2011): Corte Suprema, 6 de junio de 2011, rol 6019-2009.

Mena Mundt, Lucia de Lourdes con Corfo (2016): Corte Suprema, 16 de noviembre de 2016, rol 27830-2016. 
Monjes y otros con Arriagada y otros (2017): Juzgado Civil de Yungay, 21 de febrero de 2017, rol 347-2015.

Portuaria Cabo Froward S.A. con Servicio de Vivienda y Urbanismo Región del Bio Bío (2015): Corte de Apelaciones de Concepción, 17 de agosto de 2015, rol 470-2015.

Portuaria Cabo Froward S.A. con Servicio de Vivienda y Urbanismo Región del Bio Bío (2017): Corte Suprema, 24 de mayo de 2017, rol 17364-2015.

Ruiz Ruiz, Eduardo con Kaufmann S.A. y otros (2015): Corte Suprema, 19 de enero de 2015, rol 5299-2014.

San Martin Sánchez, Aliro con Oscar Orellana Letelier y otro (2002): Corte Suprema, 18 de abril de 2002, rol 1736-2001.

Sánchez Almarza, Fernando y otros con Cristina Comas de Fuenzalida y otros (1946 [casación forma] 1949 [casación fondo]): Corte Suprema, 11 de enero de 1946 y 11 de agosto de 1949, en RDJ, tomo XLVI, sec. $1^{\text {a }}$, p. 665.

Serrano Troncoso, María con Aravena Leal, Jaime (2014): Corte de Apelaciones de San Miguel, 14 de enero de 2014, rol 1332-2013.

Serrano Troncoso, María con Jaime Aravena Leal (2014): Corte Suprema, 28 de mayo de 2014, rol 6864-2014.

Silva Herrera, Julia Karelia con Lautaro Pinto Araya (2001): Corte de Apelaciones de Santiago, 4 de diciembre de 2001, rol 7645-1997.

Silva Herrera, Julia Karelia con Lautaro Pinto Araya (2002): Corte Suprema, 24 de octubre de 2002, rol 4305-2001.

Sociedad Inmobiliaria del Puerto Ltda. con José Miguel Tebar Martínez (2011): Corte Suprema, 28 de diciembre de 2011, rol 7081-2010.

Susaeta Sáenz de San Pedro, Eladio con Inés Echeñique Rozas y otro (2002): Corte Suprema, 29 de octubre de 2002, rol 2657-2001.

\section{SigLAS Y ABREVIATURAS}

al. alii (otros)

art. artículo

arts. artículos

CC Código Civil

Corfo Corporación de Fomento

CPC Código de Procedimiento Civil

DL decreto ley

GT Gaceta de los Tribunales

inc. inciso

Ltda. limitada

n. ${ }^{\circ}$ número

op. cit. opere citato (obra citada) 
$\frac{1}{5}$
$\frac{1}{y}$
0
0
0
0
$\frac{0}{3}$
$\frac{U}{2}$
$\frac{1}{2}$

p. página

pp. páginas

RDJ Revista de Derecho y Jurisprudencia

S.A. sociedad anónima

sec. sección

secc. secciones

S.R.L. Sociedad de Responsabilidad Limitada

ss siguientes

trad. traducción 